Volume 3 Nomor 1, Maret 2021, Halaman $71-82$.

\title{
Trauma Healing Berbasis Bermain Sambil Belajar Bagi Anak- Anak Pasca Badai Seroja Di Pulau Kera
}

\author{
Zainur Wula1), Suci Lestari Handayani' ${ }^{2)}$, Amri Adha Arifin³), \\ Fadlurrachman Hakim ${ }^{4}$, Irzani Andi Abdulrahman ${ }^{5)}$ \\ ${ }^{1,2,3,5}$ Fakultas Ilmu Sosial dan Ilmu Politik Universitas Muhammadiyah Kupang \\ ${ }^{4}$ Fakultas Ekonomi Universitas Muhammadiyah Kupang \\ Email: zainurwula1964@gmail.com ${ }^{1}$, ermaneli22@gmail.com ${ }^{2}$, \\ amriadhaarifin34@gmail.com ${ }^{3}$, fadlurrachmanhakim@gmail.com ${ }^{4}$ \\ irjanraf27@gmail.com ${ }^{5}$
}

\begin{abstract}
Abstrak
Pulau Kera merupakan wilayah di Kabupaten Kupang yang terdampak badai seroja, yang mana badai tersebut menyebabkan rumah serta perahu nelayan rusak parah akibat hantaman badai tersebut. Dari hal tersebut diatas maka Fakultas ilmu Sosial dan ilmu Politik Universitas Muhammadiyah Kupang memutuskan untuk melakukan pengabdian masyarakat dipulau tersebut. Pengabdian masyarakat berupa trauma healing terhadap anak-anak pulau Kera. Kegiatan tersebut disambut baik bukan hanya oleh anak-anak tapi juga orang tua, hal ini dibuktikan dengan hadirnya orang tua yang ikut melihat anak-anaknya menjalani proses trauma healing dari awal sampai akhir. Trauma healing adalah proses penyembuhan setelah trauma yang dilakukan agar seseorang bisa terus melanjutkan hidup tanpa mengingat hal yang membuat sakit secara psikis, Trauma sendiri pada dasarnya sering terjadi pada anak-anak serta remaja(liputan6.com). Proses trauma healing menggunakan 2 metode yaitu storytelling dan bermain sambil belajar. Storytelling dilakukan oleh para mahasiswa dengan menceritakan cerita-cerita yang dapat memancing majinasi anak sehingga terjadi proses interaksi antara mahasiswa dan anak-anak. Selanjutnya dilakukanlah proses bermain sambil belajar dimana anakanak diajarkan bernyanyi, menari sambil mengingat huruf, angka dan cara mencuci tangan yang baik dan benar, selain tu anak-anak diajarkan untuk mengasah kekompakan mereka. Hasil akhir program ini dapat terlihat pada raut wajah anakanak yang mulai ceria dan sikap terbuka.
\end{abstract}

Kata kunci: Trauma Healing; Bermain dan Belajar; Pulau Kera; Badai Seroja.

\begin{abstract}
Abtract
Kera island is an area in Kupang Regency which was affected by the storm of Seroja, which caused severe damage to houses and fishing boats as a result of the storm. From the above, the Faculty of Social and Political Sciences, University of Muhammadiyah Kupang decided to carry out community service on the island. Community service in the form of trauma healing for the children of Kera Island. This activity was welcomed not only by the children but also by the parents, this was evidenced by the presence of the parents who watched their children undergo the trauma healing process from beginning to end. Trauma healing is a process of
\end{abstract}




\section{ABDI WIRALODRA \\ ISSN 2656-5501 (Print) \\ JURNAL PENGABDIAN KEPADA MASYARAKAT \\ ISSN 2714-8041 (Online)}

healing after trauma, which is carried out so that a person can continue their life without remembering things that make them psychologically ill. Trauma itself often occurs in children and adolescents (liputan6.com). The trauma healing process uses 2 methods, namely storytelling and playing while learning. Storytelling is carried out by students by telling stories that can provoke the child's imagination so that there is a process of interaction between students and children. Furthermore, the process of playing while learning is carried out where the children are taught to sing and dance while remembering letters, numbers and how to wash their hands properly and correctly, besides the children are taught to hone their cohesiveness. During the activities the children looked happy and cheerful and there was no sad look on their faces.

Keywords: Trauma Healing, Play and Learn, Kera Island, Seroja storm. DOI: https://doi.org/10.31943/abdi.v3i1.37

\section{A. Pendahuluan}

Pada tanggal 5 april 2021 lalu provinsi NTT telah diguncang bencana berupa banjir, dan angin besar. Salah satu daerah yang terdampak bencana tersebut adalah pulau Kera, pulau Kera merupakan salah satu wilayah yang terdapat di Kabupaten Kupang, pulau seluas 43 hektar tersebut dihuni oleh lebih dari 120-an KK dengan jumlah penduduk sebanyak 1113 jiwa yang diantaranya terdapat anak-anak, dimana mereka mengalami dan merasakan bagaimana menakutkannya badai seroja yang menghantam dan menerbangkan rumah-rumah mereka yang mana hal tersebut membuat trauma tersendiri bagi anak-anak pulau Kera.

Cavanagh dalam Mental Health Channel menyatakan tentang pengertian trauma adalah suatu kejadian luar biasa yang mengguncang jiwa seseorang dimana kejadian tersebut merupakan kejadian yang jarang atau bahkan tidak pernah dialami oleh orang itu sebelumnya. Orang-orang yang mengalami trauma biasanya menjadi susah tidur, susah konsentrasi dan regulasi emosinya terganggu (Welling 2021). Ada banyak kejadian yang menyebabkan trauma seseorang seperti kehilangan, kecelakaan, rasa takut dan lain sebagainya, namun kejadian yang sama belum tentu mengakibatkan hal yang sama antara satu individu dengan individu lain (Hatta 2016).

Menurut Kaplan dan Sadock (1997) Orang bisa dikatakan mempunyai Trauma adalah mereka yang masih dalam bayangan kejadian menakutkan yang menyebabkan perubahan psikis dan tingkah laku. Menurut Rusmana (2009) perasaan trauma timbul karena adanya peristiwa luar biasa yang mengguncang 
seseorang sehingga menimbulkan rasa cemas terus menerus. Trauma secara psikologis diartikan sebagai perasaan cemas akibat peristiwa di lingkungan seseorang dimana peristiwa tersebut melampaui batas orang tersebut untuk bertahan, menghindar dan mengatasi peristiwa tersebut (Nevid, 2005). Trauma psikologis merupakan memar psikologis akibat gambaran kejadian yang membekas karena suatu guncangan kejadian yang tidak dapat diterima secara psikologis dan mengakibatkan perasaan cemas, gelisah dan menutup diri (Hatta 2016; Koentjoro and Andayani 2007; Mardiyati 2015; Pitaloka 2015; Sumiati and Sulianti 2016; Wibhowo and DS So 2019)

Menurut Schiraldi (dalam Sunardi 2006) penyebab terjadinya trauma ada 3 hal, yaitu :

1. Faktor Kesengajaan Manusia :

Meliputi segala kejadian yang memang direncanakan oleh manusia seperti peperangan, kejahatan seksual, kekerasan dalam rumah tangga yang disaksikan oleh anggota keluarga misalnya anak, penculikan, terorisme dan lain sebagainya.

2. Faktor Ketidaksengajaan Manusia

Meliputi bencana yang terjadi akibat kelalaian manusia seperti kebakaran, ledakan nuklir, runtuhnya bangunan, kehilangan bagian tubuh dan lainlain

3. Faktor Alam

Terjadi akibat perubahan alam secara mendadak seperti angin topan, banjir, tsunami, gempa bumi.

Bencana menurut Undang-Undang Nomor 24 Tahun 2007 merupakan segala peristiwa yang mengancam jiwa seseorang dan mengganggu yang mengakibatkan kerusakan serta kesakitan baik fisik maupun psikologis, bisa berupa faktor alam atau non alam yang mana terkadang hal tersebut dapat menimbulkan korban jiwa. Sedangkan definisi bencana (disaster) menurut WHO (2002) adalah kejadiankejadian alam yang merusak ekologi serta timbulnya korban jiwa dimana kejadian tersebut berskala besar sehingga perlu bantuan dari pihak luar untuk membangun kembali daerah yang terkena bencana. Dampak dari bencana tersebut salah satunya adalah menimbulkan duka yang sangat mendalam bagi korbannya dimana para 
ABDI WIRALODRA

JURNAL PENGABDIAN KEPADA MASYARAKAT
ISSN 2656-5501 (Print)

ISSN 2714-8041 (Online)

korban masih merasa pada kondisi yang tidak tenang, takut, gelisah dan mudah panik.(Nawangsih 2016)

Dari latar belakang diatas, dirasa perlu untuk melakukan sesuatu bagi khususnya anak-anak untuk mereka dapat melupakan segala trauma yang didapatkannya dari bencana yang baru saja berlalu, sebuah pelayanan secara psikologis untuk memulihkan trauma mereka yang disebut dengan trauma healing diharapkan dapat mengembalikan keadaan psikis dan senyuman manis mereka kembali.

Trauma healing adalah proses penyembuhan setelah trauma yang dilakukan agar seseorang bisa terus melanjutkan hidup tanpa mengingat hal yang membuat sakit secara psikis, Trauma sendiri pada dasarnya sering terjadi pada anak-anak serta remaja(liputan6.com).

Judith Herman (1997) seorang Psikiater berkembangsaan Amerika dalam buku menuliskan bahwa tujuan kegiatan trauma healing untuk menggerakkan 1) perasaan bahaya yang menghantui berubah ke perasaan aman dan nyaman. 2) dari berusaha denial berubah ke perasaan accepted 3) dari perasaan tertutup dan menghidar dari situasi sosial ke kemampuan untuk bersosialisasi. kegiatan trauma healing yang dilakukan oleh dosen serta mahasiswa Prodi Ilmu Politik dan Antropologi Sosial Fakultas Ilmu Sosial dan Ilmu Politik Universitas Muhammadiyah Kupang, berupa storytelling serta belajar sambil bermain dengan para peserta anak-anak pulau Kera yang berusia 5 sampai dengan 12 tahun..

\section{B. Metode}

Metode yang dilakukan dalam trauma healing ini ada beberapa tahapan, diantaranya adalah. Pertama : Persiapan, pendataan anak-anak yang ada di pulau Kera dimana anak-anak dikumpulkan dipelataran mesjid pulau kera dengan cara dipanggil melalui pengeras suara (speaker) yang ada pada mesjid, setelah itu dihitunglah jumlah anak-anak yang datang yang jumlahnya genap 100 anak.

Kedua: Pelaksanaan, anak-anak dibagi perkelompok dengan jumlah 20 orang perkelompok dan didampingi oleh kakak-kakak mahasiswa, dimana terdapat sebuah proses pendekatan antara mahasiswa dan anak-anak sehingga jarak antara mereka dipersempit agar anak-anak merasa nyaman dan senang dengan kegiatan 
trauma healing tersebut. Setelah anak-anak dibagikan alat menulis dan menggambar serta pendukung lainnya yang dapat membantu setiap proses kegiatan yang akan dilaksanakan.

Selanjutnya mahasiswa mulai kegiatan storytelling atau mendongeng sebagai terapi terhadap mereka. Mahasiswa mencoba untuk mengalihkan pikiran anak-anak dari trauma mereka ke hal-hal yang menyenangkan dengan cara melakukan kegiatan belajar sambil bermain bersama anak-anak pulau Kera, seperti mengenal abjad, berhitung, bermain sambil menari dan lain sebagainya.

Ketiga: Penutup, tahapan terakhir ini merupakan tahap dimana seluruh kegiatan ditutup sekaligus perpisahan dengan anak-anak dengan cara goyang kiri kanan maju mundur, goyang meti kei dan lain sebagainya, setelah itu para pahasiswa berpamitan pada anak-anak dan warga setempat.

\section{Hasil dan Pembahasan}

Kegiatan trauma healing merupakan salah satu dari rangkaian acara pengabdian masyarakat yang dilakukan oleh Fakultas Ilmu Sosial dan Ilmu Politik Universitas Muhammadiyah Kupang, kegiatan ini berlandaskan keprihatinan terhadap masyarakat khususnya anak-anak yang terdampak badai seroja 5 april lalu dimana data yang diperoleh menunjukkan bahwa di pulau kera terdapat banyak rumah dan kapal nelayan yang rusak dihantam badai (sindonews.com).

Rombongan berangkat ke pulau kera menggunakan 1 buah kapal ikan (Cakalang) dan 1 buah kapal motor (Boat) berukuran sedang. Waktu yang ditempuh untuk sampai ke pulau Kera adalah 1 jam dengan perjalanan yang tidak begitu mudah karena pada saat itu gelombang memang sedang tinggi. Sesampai disana rombongan langsung disambut oleh warga yang ramai-ramai membantu mengangkat barang-barang serta logistik bantuan yang telah disiapkan dari kota Kupang. 


\section{ABDI WIRALODRA \\ ISSN 2656-5501 (Print) \\ JURNAL PENGABDIAN KEPADA MASYARAKAT \\ ISSN 2714-8041 (Online)}

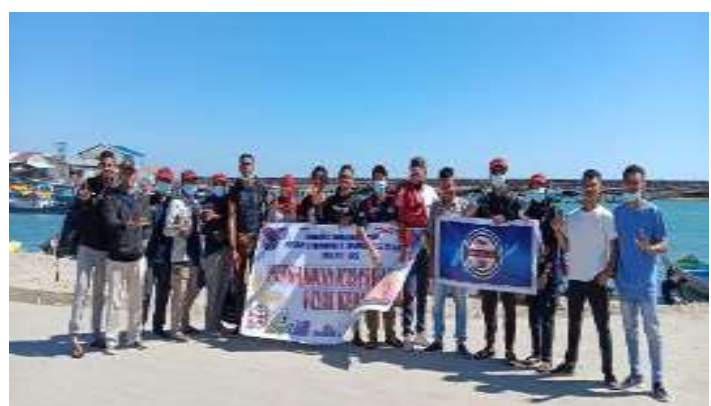

Gambar 1. Rombongan berkumpul di dermaga

Pada gambar 1, rombongan yang berjumlah 50 orang akan berangkat ke Pulau Kera. Mahasiswa telah mempersiapkan materi dan media belajar untuk membangkitkan semangat siswa dalam belajar. Selain itu dosen yang ikut serta dalam kegiatan ini juga ikut serta membimbing mahasiswa supaya dalam pelaksanaan kegiatan tidak banyak membuang waktu dan efektif membantu siswa.

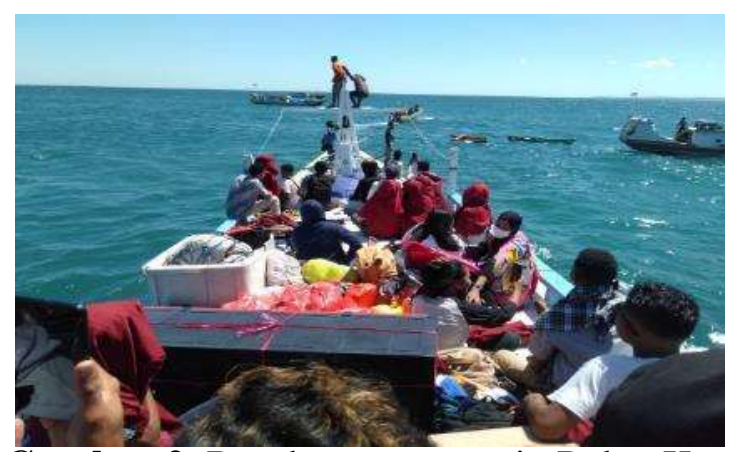

Gambar 2. Rombongan menuju Pulau Kera

Pada gambar 2, rombongan menuju Pulau Kera menggunakan satu (1) perahu cakalang dan satu (1) perahu bodi. Rombongan mendarat di pulau Kera pada siang hari. Beberapa mahasiswa mempersiapkan materi dan media untuk mengajar dan beberapa mahasiswa lainnya ikut serta mendampingi Bapak Rektor Universitas Muhammadiyah Kupang bertemu dengan warga Pulau Kera.

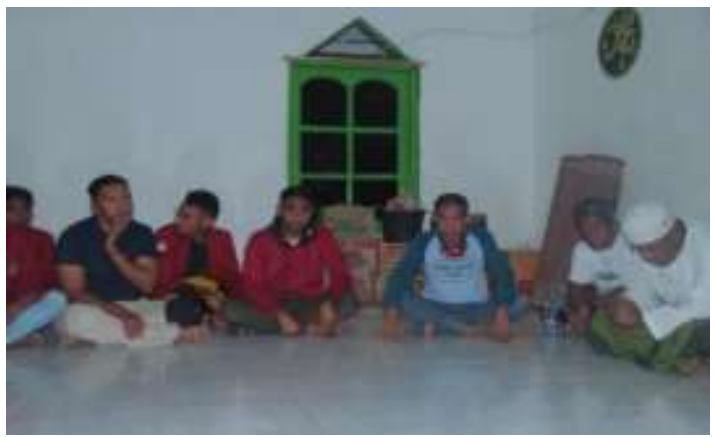

Gambar 3. Rombongan diterima oleh warga

Gambar 3 menggambarkan rombongan mahasiswa dan dosen yang dipimpin oleh Rektor Universitas Muhammadiyah Kupang, yakni bapak Dr. Zainur Wula, 
S.Pd., M.Si diterima oleh warga masyarakat pulau Kera, dilanjutkan dengan acara menyerahkan bantuan secara simbolis oleh Ketua BEM FISIPOL Universitas Muhammadiyah Kupang kepada Bapak perwakilan masyarakat pulau Kera Ust. Yusril.

Setelah acara ramah tamah selesai dilanjutkan dengan kegiatan trauma healing yang pesertanya diikuti oleh anak-anak pulau Kera yang berusia 5 sampai dengan 12 tahun, kegiatan trauma healing sendiri dilakukan oleh mahasiswa didampingi oleh ibu Suci Lestari Handayani, S.Ikom.,M.Psi (Dosen Program Studi Antropologi Sosial) dan Pak Amri Adha Arifin, S.Ip, M.Si (Dosen Program Studi Ilmu Politik) Universitas Muhammadiyah Kupang dan dibantu dengan dosen-dosen lainnya.

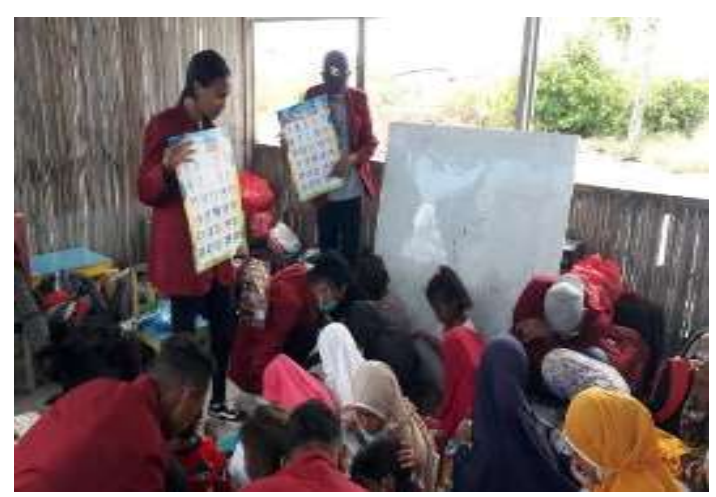

Gambar 4. Proses trauma healing dalam ruang kelas

Pada gambar 4 terlihat bahwa di ruang kelas yang terbuka mahasiswa mengajar mengenai huruf dan angka. Siswa yang berada di ruang kelas adalah siswa kelas 1 dan 2 SD. Siswa tampak antusias dalam belajar dan senang karena siswa belajar sambil bermain.

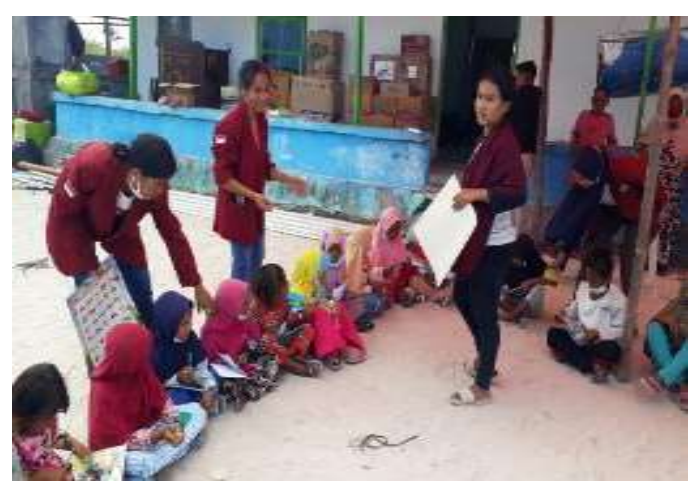

Gambar 5. Proses trauma healing dilakukan dengan santai diluar ruangan 
Pada gambar 5, mahasiswa mengajar adik - adik warga Pulau Kera dengan bermain tebak gambar dan bernyanyi. Hal ini dilakukan supaya rasa trauma akibat badai seroja di Pulau Kera dapat berkurang.

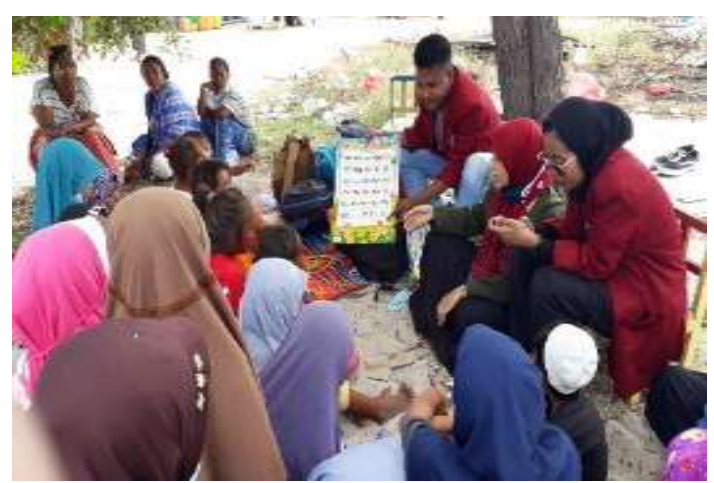

Gambar 6. Proses trauma healing disaksikan orang tua

Pada gambar 6, mahasiswa yang terdiri dari 5 orang sedang melakukan proses trauma healing. Proses trauma healing sendiri menggunakan 2 metode yaitu storytelling dan bermain sambil belajar. Storytelling atau mendongeng adalah sebuah proses membacakan atau menceritakan dongeng dan cerita rakyat kepada anak-anak dengan maksud untuk mengembangkan imajinasi dan kepekaan anak. storytelling bermanfaat untuk menumbuhkan rasa kebersamaan diantara anak-anak khususnya anak-anak korban bencana, dimana kegiatan mendongeng tersebut secara tidak langsung melatih anak-anak untuk berinteraksi dan merasakan kedekatan dengan keluarga maupun teman sebaya. Menurut Nabila (2015) storytelling mampu mengurangi rasa takut karena dengan storytelling anak-anak mampu untuk berimajinasi dan mengubah pemikiran yang tidak masuk akal menjadi masuk akal. Kegiatan mendongeng sendiri juga dapat menghilangkan rasa ketakutan atau trauma sekaligus sebagai media untuk menghibur anak-anak .(Greene,1996 dalam Syamsuddin, 2019).

Lebih lanjut menurut Syamsuddin (2019) mendongeng sebagai salah satu alternatif untuk mengobati trauma pada anak-anak dimana mendongeng sendiri perlu intuisi untuk melatih kepekaan alam bawah sadar yang merupakan inti dari pemulihan trauma. Selain itu menurut Puspitasari (2018) dengan mendongeng komunikasi antara anak dan orang tua akan terjalin, mendongeng juga dapat menjadi media penyampaian pesan dan nilai-nilai moral bagi anak, membangun imajinasi anak, mengembangkan kecerdasan emosi serta menumbuhkan minat baca. Selanjutnya mendongeng mempunyai nilai spiritual untuk menghubungkan 
perasaan dan pikiran pendongeng dengan audiensnya. Sederhananya mendongeng membutuhkan kejujuran, berbicara dari hati ke hati, interaksi yang intens dengan membuka mata, telinga dan pikiran pendongeng dengan anak-anak. Alasan mendongeng digunakan sebagai terapi karena mendongeng memberikan suasana yang menyenangkan dan hiburan kepada anak dan bukan sebagai momok menakutkan sehingga anak-anak akan ikut terapi ini dengan sendirinya tanpa paksaan dari orang tua atau pihak manapun. Hasil akhir dari terapi mendongeng sendiri diharapkan anak-anak lebih rileks dan santai serta merubah pola pikir dan cara pandang anak-anak terhadap kejadian-kejadian yang menimpa mereka dalam hal ini adalah bencana, selain itu mendongeng juga dapat membuat anak-anak lebih terhibur, kepanikan dan kecemasan perlahan-lahan berkurang.

Metode ke dua yang digunakan adalah bermain sambil belajar. Metode ini dilakukan oleh mahasiswa yang terpotret pada gambar 4 dan gambar 5. Metode ini berfungsi untuk menurunkan perilaku menghindar anak dari metode-metode penyembuhan trauma lainnya (Sumiati and Sulianti 2016). Bermain sendiri merupakan media alami untuk mengalihkan fokus mereka dari keadaan yang mencekam ke keadaan yang ceria dan bahagia (Mulyasih and Putri 2019; Murdiono, A et al. 2020; Salamor, Salamor, and Ubwarin 2020). kegiatan bermain sambil belajar yang dilakukan oleh dosen serta mahasiswa Fakultas Ilmu Sosial dan Ilmu Politik Universitas Muhammadiyah ini mengajak anak-anak untuk mengenal, huruf, angka, menulis, berhitung sambil bernyanyi dan menari, selain itu juga anakanak diajarkan untuk mencuci tangan, metode pengajarannya tetap menggunakan bernyanyi dan menari. Acara yang dilakukan pada hari minggu tanggal 2 Mei tersebut dimulai pada jam 12 siang itu dijadwalkan selesai pada jam 3 sore, namun anak-anak pulau Kera masih semangat dan antusias serta masih ingin tetap melanjutkan kegiatan tersebut dan akhirnya dilanjutkan sampai saat sebelum adzan maghrib berkumandang.

Keesokan harinya pada saat sekolah, anak-anak tersebut selain diajar oleh para guru, para mahasiswapun ikut membantu guru dalam proses belajar mengajar hingga waktu kepulangan hampir tiba. Diwaktu itu bertepatan dengan jam istirahat siswa sehingga mahasiswa dan siswa-siswa yang sebelumnya merupakan anakanak program trauma healing melakukan perpisahan di tepi pantai pulau Kera 
ABDI WIRALODRA

JURNAL PENGABDIAN KEPADA MASYARAKAT
ISSN 2656-5501 (Print)

ISSN 2714-8041 (Online)

sembari bergoyang bersama dengan diiringi oleh musik. Hal ini menunjukkan bahwa anak-anak sudah mulai pulih dari traumanya karena terlihat perbedaan sikap saat rombongan pertama kali datang dengan saat rombongan hendak pulang, dimana awalnya anak-anak masih enggan untuk dekat dengan kakak-kakak mahasiswa hingga mereka menjadi amat dekat dan bahkan ada yang tidak mau berpisah dari beberapa mahasiswa, selain itu perbedaan raut wajah yang terlihat saat awal kedatangan dengan saat akhir sesi program trauma healing yang mana saat akhir mereka terihat ceria dan amat bahagia.

\section{Kesimpulan}

Berdasarkan hasil kegiatan trauma healing pada anak di pulau Kera, terdapat beberapa simpulan yaitu ; tidak ada kendala sama sekali selama kegiatan, para tokoh masyarakat dan penduduk setempat menyambut baik kegiatan tersebut, ini dibuktikan dengan tidak hanya anak-anak yang berkumpul di pelataran mesjid pulau Kera namun para orang tua pun antusias untuk melihat kegiatan yang dilakukan oleh anak-anak mereka.

Kegiatan semacam ini perlu untuk sering diadakan di tempat-tempat atau wilayah minim hiburan serta minim fasilitas pendidikan. Kegiatan trauma healing ini sendiri terbukti dapat mengembalikan senyum anak-anak serta menciptakan rasa kedekatan antara mahasiswa dengan anak-anak pulau Kera.

\section{E. Ucapan Terima kasih}

Akhir dari penulisan jurnal pengabdian masyarakat ini kami ucapkan terima kasih kepada pihak-pihak terkait yang telah membantu jalannya pengabdian masyarakat dosen dan mahasiswa program studi Antropologi Sosial dan Ilmu Politik Fakultas Ilmu Sosial dan Ilmu Politik (FISIPOL) Universitas Muhammadiyah Kupang yaitu para civitas akademi mulai dari dekan FISIPOL, kepala LP3M dan rektor Universitas Muhammadiyah Kupang, tak lupa masyarakat pulau kera yang telah dengan tangan terbuka menerima kami disana.

\section{Daftar Pustaka}

. Undang-Undang Republik Indonesia Nomor No. 24 Tahun 2007 Tentang Penanggulangan Bencana.

Hatta, Kusumawati. 2016. Trauma Dan Pemulihannya. Aceh: Dakwah Ar-Raniry Press. 
Herman, Judith.(1997). Trauma and Recovery: The Aftermath of Violence--From Domestic Abuse to Political Terror.New York: Basic Book

Kaplan, H.I., Sadock, B.J., Grebb, J.A. 1997. Kaplan dan Sadock Sinopsis Psikiatri. Jilid Kedua. Jakarta: Bina Rupa Aksara. p 1-90

Koentjoro, Koentjoro, and Budi Andayani. 2007. "Recovery Kawasan Bencana: Perwujudan Trauma Healing Melalui Kegiatan Psikologi Dan Rohani." Unisia 30(63):3-14. doi: 10.20885/unisia.vol30.iss63.art1.

Mardiyati, Isyatul. 2015. "Dampak Trauma Kekerasan Dalam Rumah Tangga Terhadap Perkembangan Psikis Anak." Raheema 2(1):29-38. doi: 10.24260/raheema.v2i1.166.

Mulyasih, Rahmi, and Liza Diniarizky Putri. 2019. "Trauma Healing Dengan Menggunakan Metode Play Terapy Pada Anak-Anak Terkena Dampak Tsunami Di Kecamatan Sumur Propinsi Banten." Bantenese - Jurnal Pengabdian Masyarakat 1(1). doi: 10.30656/ps2pm.v1i1.1042.

Murdiono, A et al. 2020. "Simulasi Dan Trauma Healing Pasca Gempa Pada Peserta Didik SDN 1 Sambik Bangkol Nusa Tenggara Barat.” Jurnal Karinov 3(2):04.

Nabila, A. I. 2015. "Penerapan Metode Storytelling Untuk Mengurangi Rasa Takut Pada Korban Bullying Siswa Sekolah Menengah Pertama (SMP) X." Program Magister Psikologi Profesi (2003):1-21.

Nawangsih, Endah. 2016. "Play Therapy Untuk Anak-Anak Korban Bencana Alam Yang Mengalami Trauma (Post Traumatic Stress Disorder/PTSD)." Psympathic: Jurnal Ilmiah Psikologi 1(2):164-78. doi: 10.15575/psy.v1i2.475.

Nevid, Jeffrey, S. (penerjemah Tim Fakultas Psikologi Indonesia), Psikologi Abnormal, 2003, Jakarta: Penerbit Erlangga,

Pitaloka, Citra Resmi Ayu. 2015. "Pengaruh Menulis Jurnal Harian Terhadap Trauma Psikologis Pada Remaja Tuna Daksa Pasca Mengalami Kecelakaan Lalu Lintas."

Puspitasari, Nur Aini. 2018. "Keterampilan Mendongeng." 15.

Rusmana, N. (2009). Konseling Kelompok bagi Anak Berpengalaman Traumatis. Bandung: Rizqi Press.

Salamor, Anna Maria, Yonna Beatrix Salamor, and Erwin Ubwarin. 2020. "Trauma Healing Dan Edukasi Perlindungan Anak Pasca Gempa Bagi Anak-Anak Di Desa Waai." Communnity Development Journal 1(3):320.

Sumiati, and Ambar Sulianti. 2016. "Pendekatan Bermain Untuk Menurunkan Perilaku Menghindar Pada Anak Yang Mengalami Trauma Pengobatan." Psympathic: Jurnal Ilmiah Psikologi 3(1):113-20. doi: 10.15575/psy.v3i1.1099.

Sunardi, P. L. B. F. I. P. UPI. 2006. "Gangguan Stres Pasca Trauma ( Post Traumatic Stress Disorder )." 1-17.

Syamsuddin, Syamsuddin. 2019. "Pemulihan Trauma Anak-Anak Korban Gempa Di Kota Palu Melalui Mendongeng." Guru Tua: Jurnal Pendidikan Dan Pembelajaran 2(2):27-33. doi: 10.31970/gurutua.v2i2.33.

Welling, Hannah. 2021. "Mind in Motion." The Ohio State University.

Wibhowo, Christin, and Klara Andromeda DS So. 2019. "Trauma Masa Anak, Hubungan Romantis, Dan Kepribadian Ambang.” Jurnal Psikologi 46(1):63. 
doi: 10.22146/jpsi.22748. 